\title{
PROGNOSTIC FACTORS FOR POST SPINAL SURGERY INFECTION
}

\author{
By
Samy Ebrahim Al-Deeb ${ }^{1}$, Sherif Ezzat Abd Al-Aziz², Mảmoon Mohamed Abo-shosha ${ }^{2}$ and Mahmoud Mohammed Metwally ${ }^{3}$ \\ ${ }^{1}$ Mansoura international hospital, ${ }^{2}$ Department of Neurosurgery, ${ }^{3}$ Department of clinical \\ pathology, Faculty of Medicine, Al-Azhar University \\ Corresponding author: Samy Ebrahim Al-Deeb, \\ E-mail: samyeldeeb87@yahoo.com
}

\begin{abstract}
Background: Postoperative infection of the spine is a feared complication due to increased morbidity and poor patient outcomes and financial burden to health system. Prevention, early diagnosis, and successful treatment strategies are important to reducing morbidity and health care costs. Surgeons should maintain a high index of suspicion for infection and initiate proper diagnostic workup and evaluation when concerned.
\end{abstract}

Objective: The aim of this work is to review preoperative and intraoperative prognostic factors that contribute to develop surgical site infections after spine surgery and discussion of the preventive strategies to minimize risk of infection.

Patients and Methods: This is a prospective cross sectional study including 300 patients with one or more prognostic factors who underwent spinal surgeries was surveyed from January 2018 to January 2020 at different levels in neurosurgery department at Al-Hussein University Hospital and Mansoura international hospital. The patients were followed up over period of six months. When patients developed symptoms or signs of surgical site infection, patients were re-admitted to the hospital where the confirming diagnosis and proper management were done.

Results: The most relevant factors associated with post spinal surgery infections are spine level, followed by diabetes mellitus and fixation instrumentation. Less relevant factors associated with post spinal surgery infections are sex and smoking.

Conclusion: Special concern toward prognostic factors will lead to identification of high risk group, close follow up of these patients by clinical and laboratory and radiological investigations will lead to early diagnosis, early initiation of proper management and taking of preventive measures to reduce this complication.

Keywords: Spine, Surgery, Postoperative, Wound, Surgical site infection.

\section{INTRODUCTION}

Surgical site infection is one of the most serious complications following spine surgery during the postoperative stage. Surgical site infection rates have been reported to be $0.7 \%-12.0 \%$ (Fei et al., 2016). Such a broad range is most probably due to significant variation in many factors i.e. case complexity, use of instrumentation and surgical approach (Nasto et al., 2012). Staphylococcus aureus is the most common agent (Lener et al., 2018). There is an increase in Methicillin-resistant Staphylococcus aureus (MRSA) culture of spine surgery site infection recently (Patel et al., 2017). 
There are many factors that contribute to developing post-operative surgical site infection and classified to patient-related factors and procedure related factors. Patient-related factors were age, comorbidities, smoking, obesity, nutrition state, hospitalization more than week before operation, regular medications the patient was consuming (especially, steroids and other immunosuppressant drugs) and post-irradiation, which indicated that the spinal surgical site was exposed to radiation therapy in the past. Comorbidities included diabetes mellitus, hypertension, hyperlipidemia, chronic kidney disease, end stage renal disease (undergoing hemodialysis), liver cirrhosis, chronic lung disease, rheumatic disease, and malignancies (diagnosed within the last 5 years) (Manish et al., 2013). The most important procedure related factors promoting surgical site infection is site of spinal surgery, long duration of surgery, high blood loss, use of instrumentation, type of surgical approach (anterior or posterior), traumatic spine injury (Cooper et al., 2016) and the type of operations (revisions, multiple interventions) are significant factors (Klemencsics et al., 2016).

The most common presenting symptoms are pain, local tenderness, erythema, warmth and drainage. However, systemic symptoms such as fever, chills, night sweats or lethargy may develop (Attenello and Allen, 2019).

Changes in the blood count are not an absolute indicator of infection (Lazenneca et al., 2011). ESR (erythrocyte sedimentation rate) is routinely elevated in the postoperative setting; it typically is not helpful for diagnosing an acute postoperative infection (Dowdell et al., 2018). CRP (C-reactive protein) is the most sensitive indicator available to diagnose postoperative infection (Koakutsu et al., 2017). Confirming the microbial etiology of surgical site infection following spine surgery is of paramount importance to appropriately guide antimicrobial therapy (Prakash et al., 2018).

Plain radiographs are the first imaging modality used when spinal infection is suspected, but negative results do not rule out infection. MRI with gadolinium contrast has been shown to have a sensitivity of $93 \%$ and specificity of $97 \%$ for diagnosis of infection (Herrera et al., 2013).

Minor superficial infections without wound breakdown, purulence, or fluctuance may only require local wound care and antibiotics (Maruo and Berven, 2014). Surgical intervention includes debridement of nonviable tissue, obtaining tissue cultures and exploration of the wound for sinus tracts and integrity of instrumentation. Repeat debridement typically takes place 48 to 72 hours after initial debridement (Dipaola et al., 2012). Removal of instrumentation after surgical site infection of spine surgery is called for when the infection persists despite repeated serial debridement and in lateonset surgical site infection because fusion has taken place (Ariffin et al., 2018).

The aim of this work was to review the prognostic factors for post spinal surgery infection and their role in developing infection. 


\section{PATIENTS AND METHODS}

This is a prospective cross sectional study including 300 patients with one or more prognostic factors (mentioned in introduction) that underwent spinal surgeries were surveyed from January 2018 to January 2020 at different levels in neurosurgery department at Al-Hussein University Hospital and Mansoura international hospital. The patients were followed up over period of six months. When patients developed symptoms or signs of surgical site infection, patients were re-admitted to the hospital where the confirming diagnosis and proper management were done.

\section{Inclusion Criteria:}

1. Both genders.

2. Undergoing spinal surgery.

3. Patients have one or more of factors (mentioned in introduction).

\section{Exclusion Criteria:}

1. Patients do not have any factors mentioned above.

2. Age $<15$ years.

3. Patients with uncontrolled unchangeable factors such as cardiovascular disease and diabetes mellitus.

\section{Evaluation of cases:}

All patients will be followed up after surgery by:

\section{Clinical:}

Pain after discomfort free period, constitutional symptoms, wound dehiscence, discharge from incision site.

\section{Laboratory investigations:}

CBC, CRP, ESR, liver and kidney functions and culture from wound dehiscence or during surgical exploration.

\section{Radiology:}

Plain x-ray and MRI spine with contrast.

\section{Statistical Analysis:}

Data were coded and entered using the statistical package for the Social Sciences (SPSS) version 26 (IBM Corp., Armonk, NY, USA). Data were summarized using mean, standard deviation, median, minimum and maximum in quantitative data and using frequency (count) and relative frequency (percentage) for categorical data. For comparing categorical data, Chi square ( $\square 2$ ) test was performed. Exact test was used instead when the expected frequency is less than 5. P-values less than 0.05 were considered as statistically significant.

\section{RESULTS}

This study included 300 patients (190 males and 110 females) with one or more prognostic factors (mentioned in introduction) that underwent spinal surgeries for different indications at different spine levels. The mean age of presentation is $48.92 \pm 12.21,228$ patients are below 60 years and 72 patients are above 60 years. 198 patients operated at lumbar region, 77 at cervical region, 14 at dorsal region and 11 at dorsolumbar junction. Age above 60 years was associated with infection prevalence of $13.3 \%$ within infected group and $1.3 \%$ 
within whole age group. Age below 60 years was associated with infection prevalence of $11.4 \%$ within infected group and $86.7 \%$ within whole age group. Male sex was associated with infection prevalence of $63.3 \%$ within infected group and $6.3 \%$ within whole patients. Female sex was associated with infection prevalence of $36.7 \%$ within infected group and $3.7 \%$ within whole patients. Lumbar region was associated with infection prevalence of $80 \%$ within infected cases and $8 \%$ within whole patients. Dorsal region was associated with infection prevalence of $6.7 \%$ within infected cases and $0.7 \%$ within whole patients. Dorsolumbar junction was associated with infection prevalence of $10 \%$ within infected cases and $10 \%$ within whole patients. Cervical region was associated with infection prevalence of $3.3 \%$ within infected cases and $0.3 \%$ within whole patients (Table 1).

Table (1): Distribution of studied patients according to age, sex and spine level

\begin{tabular}{|c|c|c|c|c|c|c|c|}
\hline & Mean & $\begin{array}{l}\text { Standard } \\
\text { Deviation }\end{array}$ & Median & Minimum & \multicolumn{2}{|c|}{ Maximum } & \multirow{4}{*}{$P$ value } \\
\hline \multirow[t]{3}{*}{ Age } & 48.92 & 12.21 & 51.00 & 18.00 & \multicolumn{2}{|c|}{75.00} & \\
\hline & & & \multirow[b]{2}{*}{ Count } & \multirow[b]{2}{*}{$\%$} & Infection & revalence & \\
\hline & & & & & $\begin{array}{c}\text { Infected } \\
\text { group }\end{array}$ & $\begin{array}{c}\text { Whole } \\
\text { patients }\end{array}$ & \\
\hline \multirow{2}{*}{$\begin{array}{l}\text { Age } \\
\text { groups }\end{array}$} & \multicolumn{2}{|c|}{$>60$ years } & 72 & $24.0 \%$ & $13.3 \%$ & $1.3 \%$ & \multirow{2}{*}{0.149} \\
\hline & \multicolumn{2}{|c|}{$<60$ years } & 228 & $76.0 \%$ & $11.4 \%$ & $86.7 \%$ & \\
\hline \multirow{2}{*}{ Sex } & & Male & 190 & $63.3 \%$ & $63.3 \%$ & $6.3 \%$ & \multirow{2}{*}{1} \\
\hline & & male & 110 & $36.7 \%$ & $36.7 \%$ & $3.7 \%$ & \\
\hline \multirow{4}{*}{ Level } & & Imbar & 198 & $66.0 \%$ & $80 \%$ & $8 \%$ & \multirow{4}{*}{0.002} \\
\hline & & orsal & 14 & $4.7 \%$ & $6,7 \%$ & $0.7 \%$ & \\
\hline & & rvical & 77 & $25.7 \%$ & $10 \%$ & $10 \%$ & \\
\hline & \multicolumn{2}{|c|}{ Dorsolumbar } & 11 & $3.7 \%$ & $3.3 \%$ & $0.3 \%$ & \\
\hline
\end{tabular}

According to patient-related prognostic factors, 120 patients were smoker, 96 patients were diabetic, 13 patients were on corticosteroid therapy, 116 patients have other chronic diseases, 129 patients are obese, 70 patients have neurological defect and no cases of malnutrition included. Smoking was associated with infection prevalence of $36.7 \%$ within infected cases and 3.7 within whole patients. Obesity is associated with infection prevalence of $30 \%$ within infected cases and 3\% within whole patients. Corticosteroid use was associated with infection prevalence of $10 \%$ within infected cases and $1 \%$ within whole patients. Other diseases were associated with infection prevalence of $30 \%$ within infected cases and 3\% within whole patients. Neurological defect was associated with infection prevalence of $10 \%$ within infected cases and $1 \%$ within whole patients. DM was associated with infection prevalence of $40 \%$ within infected cases and 4\% within whole patients (Table 2). 
Table (2): Distribution of patients with patient-related prognostic factors

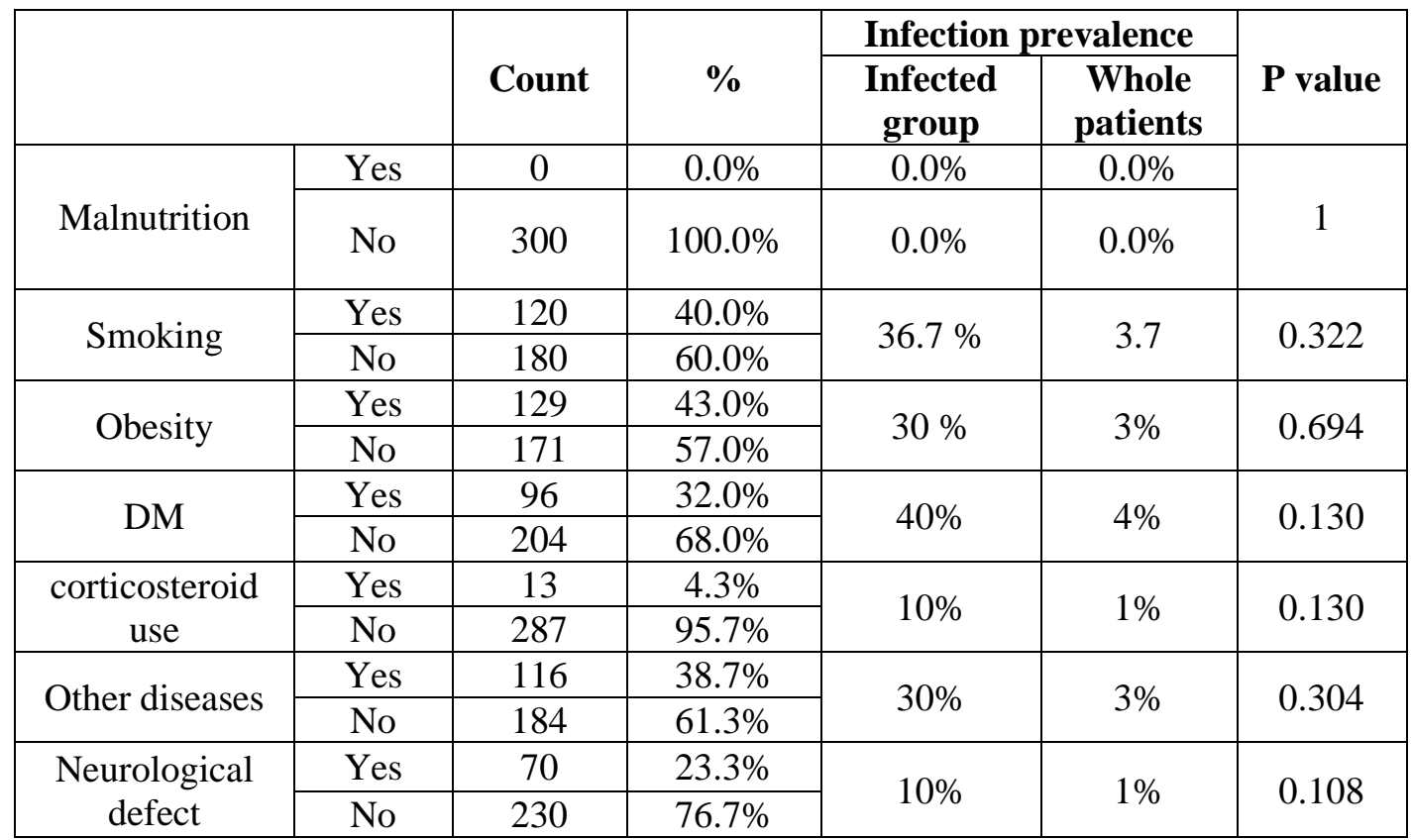

According to procedure-related prognostic factors, 86 patients are trauma patients, 157 patients operated by fixation instruments, 7 patients have blood transfusion. Trauma was associated with infection prevalence of $23.3 \%$ within infected cases and $2.3 \%$ within whole patients. Blood transfusion was associated with infection prevalence of $6.7 \%$ within infected cases and $0.7 \%$ within whole patients. Fixation instrumentation is associated with infection prevalence of $56.7 \%$ within infected cases and $5.7 \%$ within whole patients (Table 3).

Table (3): Distribution of patients with procedure-related prognostic factors

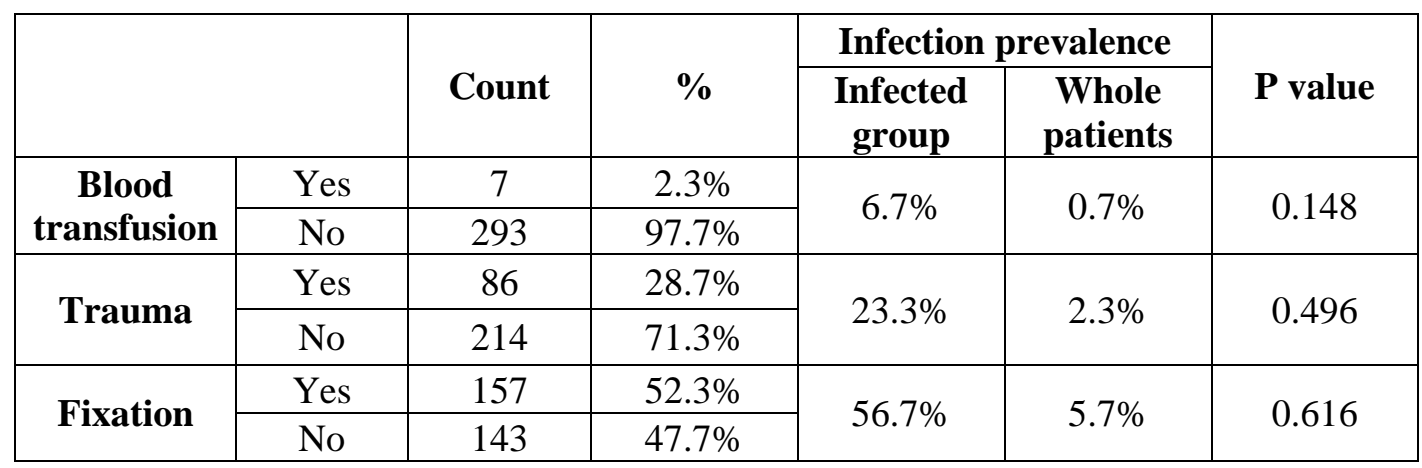

Thirty patients developed signs and symptoms of surgical site infection, while 270 patients were free. In this study the prevalence of post spinal surgery infection is $10 \%$ (Table 4). 
Table (4): Distribution of studied patients according occurrence of surgical site infection

\begin{tabular}{|c|c|c|c|}
\hline \multicolumn{2}{|c|}{} & Count & \% \\
\hline \multirow{2}{*}{ infection } & infected group & 30 & $10.0 \%$ \\
\cline { 2 - 4 } & non infected group & 270 & $90.0 \%$ \\
\hline
\end{tabular}

As regards of symptoms of postoperative surgical site infection in late infection, pain occurred in $100 \%$ of cases. In early infection, pain occurred in $60 \%$ of cases. Other symptoms and signs of postoperative surgical site infection, in late infection were swelling at surgical site
(17\%), neurological defect (12\%), fever $(6 \%)$, radiculopathy $(17 \%)$ and systemic manifestation (6\%). In early infection, wound discharge in 53\%, wound dehiscence in $80 \%$, fever and systemic manifestation in 6\% (Table 5).

Table (5): Early and symptoms and signs

\begin{tabular}{|c|c|c|c|}
\hline \multirow{4}{*}{ Late } & symptoms & Count & \% \\
\cline { 2 - 4 } & Pain & 15 & $100 \%$ \\
\cline { 2 - 4 } & Swelling & 3 & $17 \%$ \\
\cline { 2 - 4 } & Neurological defect & 2 & $12 \%$ \\
\cline { 2 - 4 } & fever & 1 & $6 \%$ \\
\cline { 2 - 4 } & Radiculopathy & 3 & $17 \%$ \\
\cline { 2 - 4 } & Systemic symptoms & 10 & $6 \%$ \\
\hline \multirow{4}{*}{ Early } & pain & 13 & $35 \%$ \\
\cline { 2 - 4 } & Wound discharge & 1 & $60 \%$ \\
\cline { 2 - 4 } & dehiscence & 1 & $6 \%$ \\
\cline { 2 - 4 } & fever & & $6 \%$ \\
\cline { 2 - 4 } & Systemic manifestation & & \\
\cline { 2 - 4 } & & & 13 \\
\hline
\end{tabular}

No medical complications occurred in $93.3 \%$ of cases, permanent renal dialysis in $3.30 \%$ and death in $3.30 \%$ of cases.
These complications were due to prolonged use of nephrotoxic drugs and toxemia (Table 6).

Table (6): Medical complications in infected cases

\begin{tabular}{|c|c|c|c|}
\hline \multirow{3}{*}{ Complication } & Count & \% \\
\cline { 2 - 4 } & renal dialysis & 1 & $3.3 \%$ \\
\cline { 2 - 4 } & Toxemia and death & 1 & $3.3 \%$ \\
\hline
\end{tabular}

All cases in infected group were operated by posterior approach. Laminectomy and fixation was associated with highest rate of infection (50\%), followed by discectomy (33.3\%), and followed by laminectomy alone (10\%).
Multiple operations were associated with $10 \%$ of infection in infected group. Multiple operations are associated with $10 \%$ of infection in infected group (Table 7). 
Table (7): Distribution of infected cases according to type of operation

\begin{tabular}{|c|c|c|c|}
\hline \multicolumn{2}{|c|}{} & \multicolumn{2}{c|}{ infected group } \\
\cline { 3 - 4 } & laminectomy & Count & $\%$ \\
\hline \multirow{3}{*}{ Operation done } & Laminectomy and fixation & 3 & $10.0 \%$ \\
\cline { 2 - 4 } & Laminectomy and vertebroplasty & 1 & $50.0 \%$ \\
\cline { 2 - 4 } & discectomy & 10 & $3.3 \%$ \\
\cline { 2 - 4 } & discectomy and fixation & 1 & $33.3 \%$ \\
\hline \multirow{2}{*}{ multiple operations } & yes & 3 & $10.0 \%$ \\
\cline { 2 - 4 } & no & 27 & $90.0 \%$ \\
\hline
\end{tabular}

Culture results was MRSA in $23.3 \%$ of infected cases followed by staph aureus in $16.7 \%$, streptococcus viridians in $10 \%$, enterococci in $3.3 \%$, gram + bacilli in
$3.3 \%$, acinetobacter in $6.7 \%$, E-coli in $3.3 \%$, staph epidermidis in $13.3 \%$, pseudomonas in $3.3 \%$ and no growth in $16.7 \%$ (Table 8).

Table (8): Culture results

\begin{tabular}{|c|c|c|c|}
\hline \multicolumn{2}{|c|}{} & \multicolumn{2}{c|}{ infected group } \\
\cline { 2 - 4 } & streptoco viridans & Count & $\%$ \\
\hline \multirow{4}{*}{ Organism } & staph epidemidis & 4 & $10.0 \%$ \\
\cline { 2 - 4 } & staph aureus & 5 & $13.3 \%$ \\
\cline { 2 - 4 } & pseudmonas & 1 & $16.7 \%$ \\
\cline { 2 - 4 } & MRSA & 7 & $3.3 \%$ \\
\cline { 2 - 4 } & gram + & 1 & $23.3 \%$ \\
\cline { 2 - 4 } & enterobacter & 1 & $3.3 \%$ \\
\cline { 2 - 4 } & E-coli & 1 & $3.3 \%$ \\
\cline { 2 - 4 } & acinetobacter & 2 & $6.7 \%$ \\
\cline { 2 - 4 } & no & 5 & $16.7 \%$ \\
\hline
\end{tabular}

As regard management, conservative treatment done in 2 patients, wound exploration and debridement with primary suture in 18 patients, debridement with secondary suture in 4 patients, debridement with removal of fixation system done in 4 patients, debridement with fixation in one patient and evacuation of epidural abscess in one patient (Table 9).

Table (9): Management done in infected cases

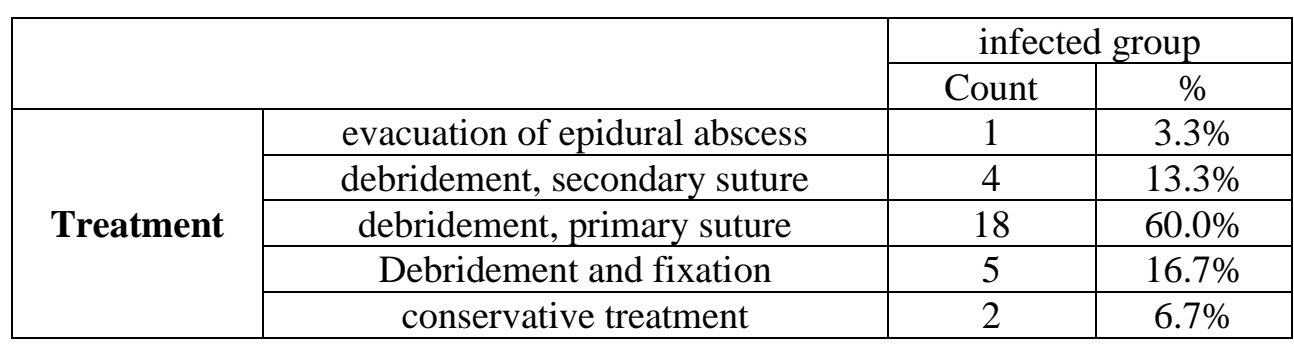




\section{DISCUSSION}

In this study, age, smoking, obesity, regular medications the patient was consuming (steroids and other immunosuppressant drugs), acute spine injury, neurological defect and comorbidities included diabetes mellitus, hypertension, chronic kidney disease, end stage renal disease (undergoing hemodialysis), liver cirrhosis, chronic lung disease, rheumatic diseases, and cardiac problems were identified as factors for surgical site infection after spinal surgery, and all these factors were preoperative patient-related factors. Besides that, surgical procedures, type of approach, use of fixation instrumentation and Martials like bone cement and bone granules and blood transfusion were identified as preoperative procedurerelated factors. No cases of malnutrition, prolonged preoperative hospitalization, malignancy and spinal tumors included. The prevalence of post spinal surgery infection was $10 \%$. This was correlated with Fei et al. (2016) who reported infection rates between $0.7 \%-12.0 \%$.

Male sex was associated with infection prevalence of $63.3 \%$ within infected group and $6.3 \%$ within whole patients. Female sex was associated with infection prevalence of $36.7 \%$ within infected group and $3.7 \%$ within whole patients. This was correlated with finding of Manish et al. (2013) who reported that male is at high risk than females.

As regards of symptoms of postoperative surgical site infection in late infection, pain occurred in $100 \%$ of cases. In early infection, pain occurred in $60 \%$ of cases. This was correlated with finding of Parchi et al. (2015) who reported that back pain is the most reliable symptom and is present in $83 \%$ to $100 \%$ of patients in the general population. Other symptoms and signs of postoperative surgical site infection, in late infection were swelling at surgical site $(17 \%)$, neurological defect $(12 \%)$, fever (6\%), radiculopathy $(17 \%)$ and systemic manifestation (6\%). In early infection, wound discharge in $53 \%$, wound dehiscence in $80 \%$, fever and systemic manifestation in $6 \%$. This was correlated with findings of Dowdell et al. (2018) who reported that the most common physical sign of infection is erythema or swelling of the incision. They mentioned that obvious signs of infection are wound dehiscence and purulent drainage from the wound. Fever is present in less than half of patients $(40 \%)$ and other signs and symptoms include fatigue and even weight loss depending on the chronicity of the infection.

No medical complications occurred in 93.3\% of cases, permanent renal dialysis in $3.30 \%$ and death in $3.30 \%$ of cases. These complications were due to prolonged use of nephrotoxic drugs and toxemia. Age above 60 years was associated with infection prevalence of $13.3 \%$ within infected group and $1.3 \%$ within whole age group. Age below 60 years was associated with infection prevalence of $11.4 \%$ within infected group and $86.7 \%$ within whole age group. There was no correlation between old age and occurrence of infection. This was correlated with Manoso et al. (2014) who found that old age patients with other comorbidities were at an increased risk for surgical site infection but age alone was not an independent factor. 
Smoking has no significant association with surgical site infection. Obesity is associated with infection prevalence of 30 $\%$ within infected cases and 3\% within whole patients. Corticosteroid use was associated with infection prevalence of $10 \%$ within infected cases and $1 \%$ within whole patients. Other diseases were associated with infection prevalence of $30 \%$ within infected cases and 3\% within whole patients. Neurological defect was associated with infection prevalence of $10 \%$ within infected cases and $1 \%$ within whole patients. There was no correlation between these factors and occurrence of infection. We believe that these factors were commonly associated with each other and other factors. Which was correlated with Yao et al. (2018) who found that these factors are independent factors.

Trauma was associated with infection prevalence of $23.3 \%$ within infected cases and $2.3 \%$ within whole patients. Trauma was almost associated with fixation instrumentation and neurological defect. This was correlated with Dubory et al. (2015) who found that patients with traumatic spine injury had increase severity of a surgical site infection.

DM was associated with infection prevalence of $40 \%$ within infected cases and $4 \%$ within whole patients. This was correlated with Parker et al. (2011) who found that postoperative wound infections in diabetic patients have been reported up to $24 \%$.

Fixation instrumentation was associated with infection prevalence of $56.7 \%$ within infected cases and 5.7\% within whole patients. Laminectomy and fixation was associated with highest rate of infection (50\%), followed by discectomy $(33.3 \%)$, and followed by laminectomy alone (10\%). Multiple operations were associated with $10 \%$ of infection in infected group. This is correlated with Pawar and Biswas (2016) who reported that less invasive interventions, such as discectomy, have been reported to have a lower incidence of postoperative infection as opposed to more invasive techniques, as an instrumented fusion which has the highest reported rates of postoperative infection. Blood transfusion has no significant association with postoperative surgical site infection.

All cases in infected group operated by posterior approach, which was correlated with Yao et al. (2018) who found that anterior approach often has very low risk of infection compared to posterior approach.

The significant $\mathrm{P}$-value found in this study was associated with spine level. Lumbar region was associated with infection prevalence of $80 \%$ within infected cases and $8 \%$ within whole patients. Dorsal region was associated with infection prevalence of $6.7 \%$ within infected cases and $0.7 \%$ within whole patients. Dorsolumbar junction was associated with infection prevalence of $10 \%$ within infected cases and $1 \%$ within whole patients. Cervical region was associated with infection prevalence of $3.3 \%$ within infected cases and $0.3 \%$ within whole patients. This was correlated with Dessy et al. (2017) who reported highest infection rate in lumbar patients and lowest rate in cervical patients.

Culture results was MRSA in $23.3 \%$ of infected cases followed by staph aureus in 
$16.7 \%$, streptococcus viridians in $10 \%$, enterococci in $3.3 \%$, gram + bacilli in $3.3 \%$, acinetobacter in $6.7 \%$, E-coli in $3.3 \%$, staph epidermidis in $13.3 \%$, pseudomonas in $3.3 \%$ and no growth in $16.7 \%$. This was correlated with Patel et al. (2017) who found an increase in MRSA culture of spine surgery site infection and average proportion of surgical site infections attributable to MRSA was $37.9 \%$.

Management was based on many considerations such as time of presentation, wound condition, general condition, instrumentation, fusion, MRI, neurological condition and pain.

\section{CONCLUSION}

Special concern toward prognostic led to identification of high risk group. Close follow up of these patients by clinical, laboratory investigations and radiological investigations led to early diagnosis, early initiation of proper management and taking of preventive measures to reduce this complication.

Conflict of interest: The authors declare no conflict of interest.

Funding sources: The authors have no funding to report.

\section{REFERENCES}

1. Ariffin HM, Kawaguchi $Y$, and Wong $C$ (2018): Instrumentation and Spinal Infections. AOSpine Masters Series, 10(4):33-39.

2. Attenello J and Allen T (2019): Postoperative Spine Infections. Seminars in Spine Surgery, 31(4): 53-75.

3. Cooper K, Glenn CA, Martin M, Stoner J, Li J and Puckett T (2016): Risk factors for surgical site infection after instrumented fixation in spine trauma. J Clin Neurosci, 23:123-127.
4. Dessy AM, Yuk FJ, Maniya AY, Connolly JG, Nathanson JT, Rasouli J and Choudhri TF (2017): Reduced Surgical Site Infection Rates Following Spine Surgery Using an Enhanced Prophylaxis Protocol. Cureus, 9(4):77-83.

5. Dipaola CP, Saravanja DD, Boriani L, Zhang H, Boyd MC, Kwon BK, Paquette SJ, Dvorak MF, Fisher CG and Street JT (2012): Postoperative infection treatment scores for the spine: construction and validation of a predictive model to define need for single versus multiple irrigation and debridement for spinal surgical site infection. Spine J, 12:18-30.

6. Dowdell J, Brochin R, Kim J, Overley S, Oren J, Freedman B and Cho $S$ (2018): Postoperative Spine Infection: Diagnosis and Management. Global Spine Journal, 8(4S): 3743.

7. Dubory A, Giorgi $H$ and Walter A (2015): Surgical-site infection in spinal injury: incidence and risk factors in a prospective cohort of 518 patients. Eur Spine J, 24:543554 .

8. Fei Q, Li J, Lin J, Li D, Wang B, Meng H, wang Q, Su N and Yang Y (2016): Risk Factors for Surgical Site Infection after Spinal Surgery: A Meta-Analysis. World Neurosurgery, 95:507-515.

9. Herrera IH, Presa RM, Guti'errez RG, Ruiz EB and Benassi JMG (2013): Evaluation of the postoperative lumbar spine. Radiologia, 55:12-23.

10. Klemencsics I, Lazary A and Szoverfi $Z$ (2016): Risk factors for surgical site infection in elective routine degenerative lumbar surgeries. Spine J, (16)11:1377-1383.

11. Koakutsu T, Sato $T$, Aizawa $T$, Itoi $E$ and Kushimoto $S$ (2017): Postoperative changes in presepsin level and values predictive of surgical site infection after spinal surgery: a single center, prospective observational study, Spine (Phila Pa 1976), 43(8):578-584

12. Lazenneca JY, Fourniolsa E, Lenoirb T, Aubryc A, Pissonniera ML, Issartel B and Rousseaua MA (2011): Infections in the operated spine: Update on risk management 
and therapeutic strategies. Orthopaedics \&Traumatology: Surgery and Research, 97S: 107-116.

13. Lener S, Hartmann S, Giuseppe MV, Certo F, Thomé $C$ and Tschugg A (2018): Management of spinal infection: a review of the literature. Acta Neurochirurgica 160:487496.

14. Manish K, Lee A and Vincent C (2013): Infection with spinal instrumentation: Review of pathogenesis, diagnosis, prevention, and management. Surg Neurol Int, (4): 392-403.

15. Manoso MW, Cizik AM, Bransford RJ, Bellabarba C, Chapman $J$ and Lee MJ (2014): Medicaid status is associated with higher surgical site infection rates after spine surgery. Spine (Phila Pa 1976), 39:1707-1713.

16. Maruo K and Breven SH (2014): Outcome and treatment of postoperative spine surgical site infections: predictors of treatment success and failure. J Ortho Sci, 19(3):393-404.

17. Nasto LA, Colangelo D, Rossi B, Fantoni M and Pola E (2012): Postoperative spondylodiscitis. European Review for Medical and Pharmacological Science 16:50-57.

18. Parchi PD, Evangelisti G, Andreani L, Girardi F, Darren L, Sama A and Lisanti $M$ (2015): Postoperative spine infections. Orthopedic Reviews, 7(3): 56-62.
19. Parker SL, Adogwa O, Witham TF, Aaronson OS, Cheng J and Mcgirt MJ (2011): Post-operative infection after minimally invasive versus open transforaminal lumbar interbody fusion (TLIF): literature review and cost analysis. Minimal Invasive Neurosurgy, 54(1):33-37.

20. Patel H, Khoury H, Girgenti D, Welner Sh and Yu H (2017): Burden of surgical site infections associated with select spine operations and involvement of staphylococcus aureus. Surgical Infections, 18(4):461-73.

21. Pawar AY and Biswas SK (2016): Postoperative spine infections. Asian Spine Journal, 10:176-183.

22. Prakash AC, Prakash A and Sahay CB (2018): Postoperative Spinal Wound Infection in Neurosurgical wards at RIMS, a Single Centre Experience. IOSR Journal of Dental and Medical Sciences, 17(2):20-24.

23. Yao R, Theodore J, Zhou H, Brian $K$ and Street J (2018): Surgical Site Infection in Spine Surgery: Who Is at Risk? Global Spine Journal, 8(4S) 5-30. 
عو امل التكهن بعدوى ما بعد جر احة العمود الفقري سامى إبراهيم الايب، شريف عزت عبد العزيز، مسأمون محمد أبو شوشة، محمود محمد العدود متولى

قسم جراحة المخ والأعصاب و الباثولوجيا الإكلينيكية، كلية الطب، جامعة الأزهر

E-mail: samyeldeeb87@yahoo.com

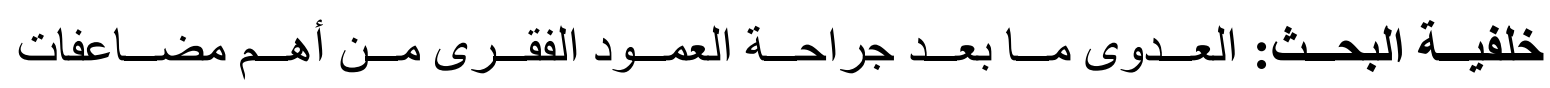

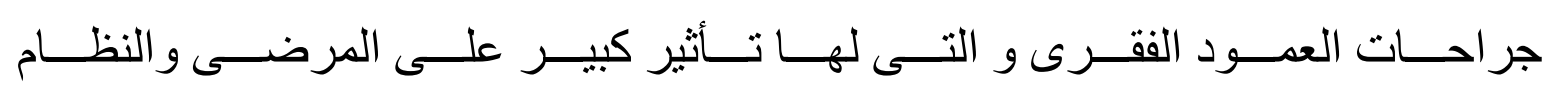

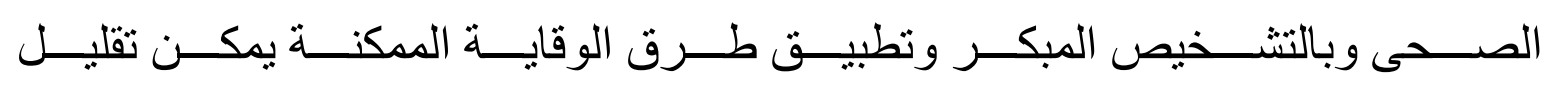
تلك المشكلات وتوفير رعاية أفضل للمرضى.

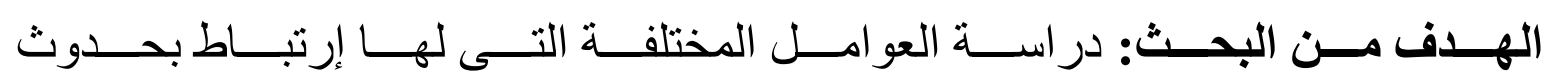

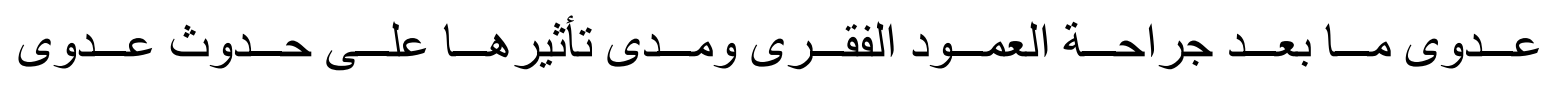

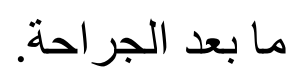

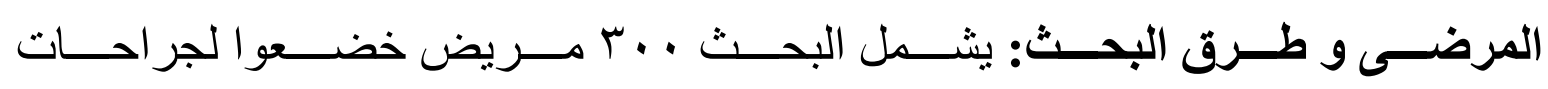

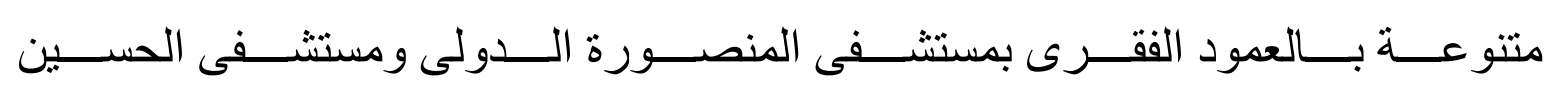

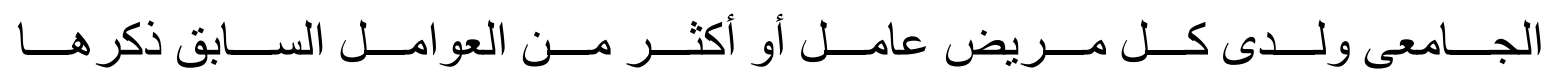

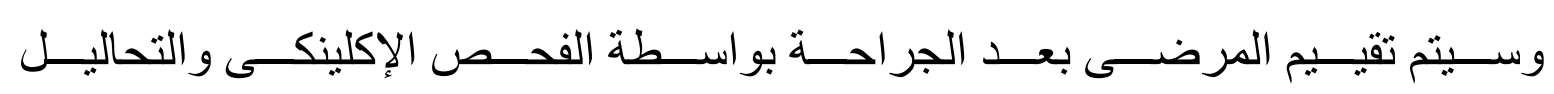

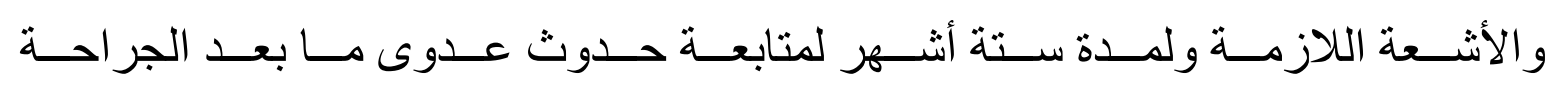

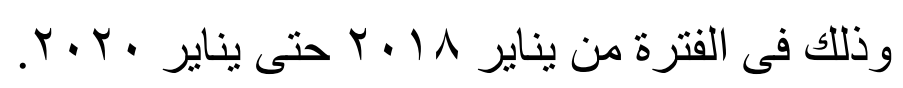

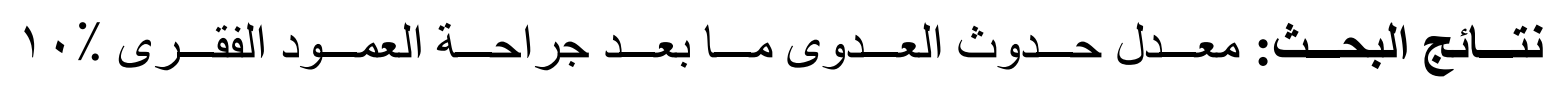

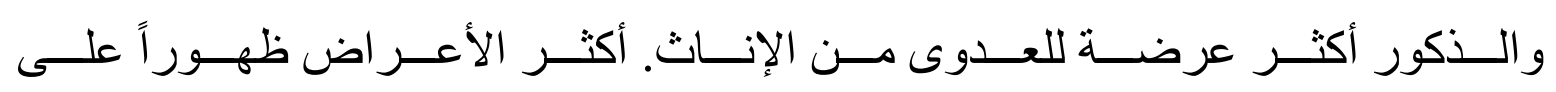

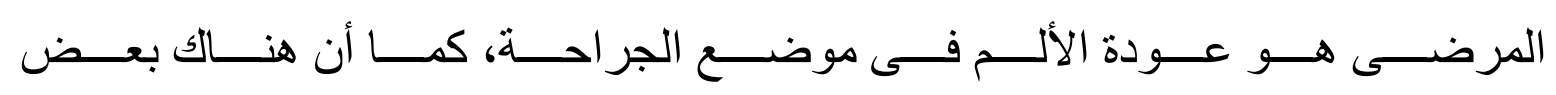

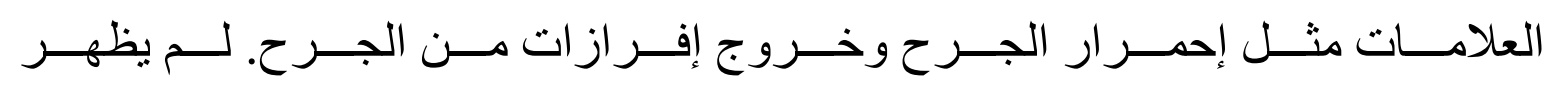

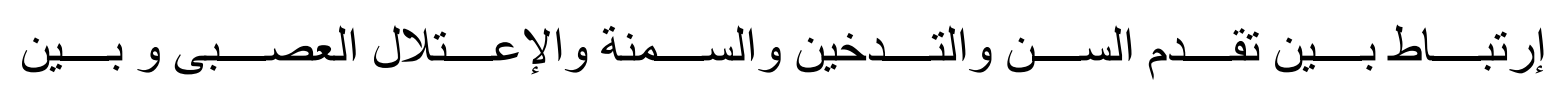




\section{PROGNOSTIC FACTORS FOR POST SPINAL SURGERY INFECTION}

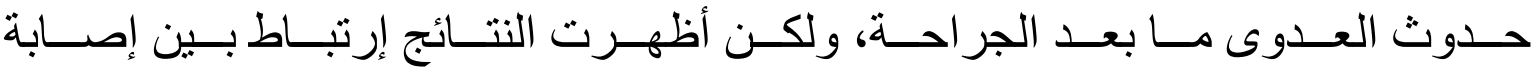

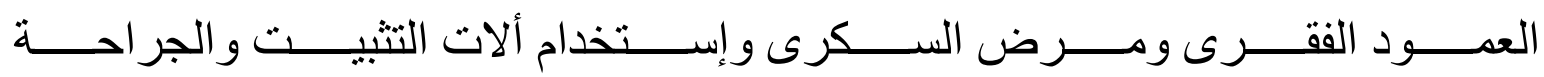

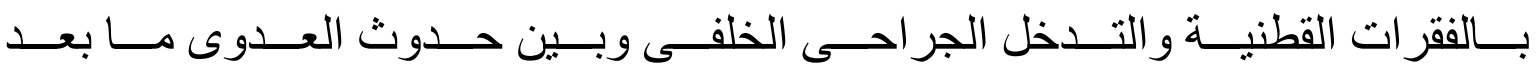

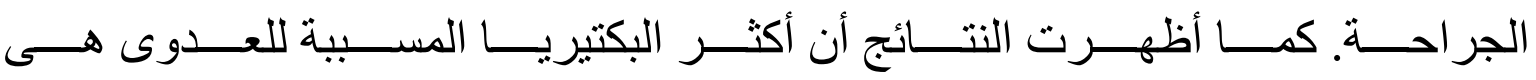
بكتيريا المكورة العنقودية المقاومة للميثيسلين.

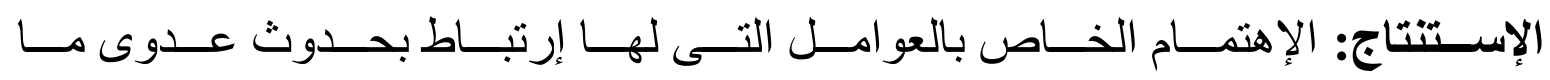

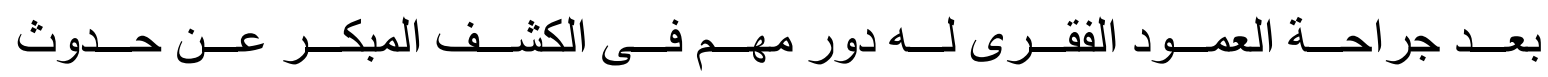

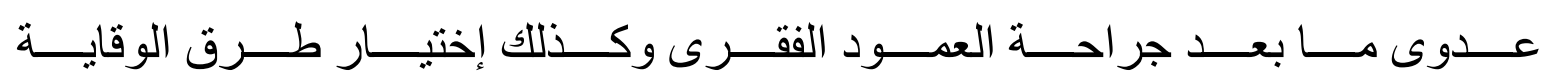
المناسبة لتقليل حدوث العدوى. الكلمات الدالة: عدوى ما بعد الجر احة ــ العمود الفقرى 